\title{
O VALOR ÉTICO NO ENSINO DA ENFERMAGEM
}

\author{
The Ethical Value in the Nursing education
}

\section{El valor etico en la educación del oficio de enfermería}

Gilberto de Lima Guimarães ${ }^{1}$

Lígia de Oliveira Viana ${ }^{2}$

\section{RESUMO}

0 presente artigo é fruto da tese apresentada à Escola de Enfermagem Anna Nery, na linha de Pesquisa em Educação e Enfermagem, balizada na Teoria de Valor. A Enfermagem possui um conjunto de valores do qual se nutre para elaborar uma escala. Objetivo: compreender o Valor Ético, no discurso do enfermeiro-docente, à frente do ato de educar, e que ele transmite ao educando, e discuti-lo à luz dos pressupostos de Max Scheler. A metodologia é qualitativa, centrada no enfoque fenomenológico. 0 cenário foram três instituições de ensino superior de Enfermagem, localizadas na cidade do Rio de Janeiro. 0 período de realização foi de agosto de 2007 a junho de 2008. Resultados: o Valor Ético emerge no discurso do enfermeiro-docente no ato de educar como fundante. Conclusão: por meio do discurso, o enfermeiro apresenta o Valor Ético ao educando, ratificando-o como instituinte para a práxis assistencial da Enfermagem.

Palavras-chave: Educação. Enfermagem. Cultura.

\begin{abstract}
The current article comes from the Thesis, presented to the Nursing School Anna Nery, following the line of a Research in Education and Nursing, based on the Value Theory. The nursing possess a group of values which nourishes itself to elaborate a scale. Objective: understand the Ethical Value, in the speech of the nurse-professor, focused to the act of educating, that he/ she transmits to the student and discuss it under the light of the assumptions of Max Scheler. The methodology is qualitative, focused in the phenomenological approach. The scenario has been three institutions of superior education in nursing, located in the city of Rio de Janeiro. The period of accomplishment was from August of 2007 to June of 2008. Results: Ethical value emerges in the speech of the nurse-professor in the act of educating as a foundation. Conclusion: by means of the speech the nurse presents Ethical value to the student, ratifying it as establishment for the assisting praxis of nursing.
\end{abstract}

Key Word: Education. Nursing. Culture

\section{Resumen}

El presente artículo es fruto de la Tesis, presentada a la Escuela de Enfermería Anna Nery, en la línea de investigación en Educación y Enfermería, enmarcada en la Teoria de Valor. La enfermería tiene un conjunto de valores de la cual se nutre para elaborar una escala. Objetivo: comprender el Valor Ético, en el discurso del enfermero-docente, frente al acto de educar y que transmite al ir educando, Discutido a la luz de los supuestos de Max Scheler. La metodologia es qualitativa, centrada en el enfoque fenomenológico. El marco del presente estudio fueron tres instituiciones de enseñaza superior de enfermería, ubicadas en la ciudad do Rio de Janeiro. El período de realización del estudio fue de agosto de 2007 a junio 2008. Resultados: el Valor Ético aparece en el discurso del enfermero-docente en el acto de educar como fundamento.. Conclusión: a través del discurso, el enfermero presenta el Valor Ético al educado, ratificándolo como parte integrante dela praxis asistencial de la enfermería.

Palabras chaves: Educación. Enfermería. Cultura

\footnotetext{
'Doutor em Enfermagem. Coordenador do Curso de Enfermagem do Centro Universitário de Caratinga - MG. RT da Clínica de Terapia Renal - Clirenal/ Caratinga. Membro do Núcleo de Pesquisa em Educação, Saúde e Enfermagem - NUPESENF; EEAN/ UFRJ. Brasil. E-mail: gilberto@funec.br, ${ }^{2}$ Professora Titular do Departamento de Metodologia da EEAN/UFRJ. Membro do Núcleo de Pesquisa em Educação, Saúde e Enfermagem - NUPESENF, EEAN/UFRJ. Brasil. E-mail: ligiaviana@uol.com.br
} 
O Valor Ético IIO eIISIIIO da Elifermagem

Gimarães GL, Viana LO

\section{INTRODUÇÃO}

O presente artigo éfruto da tese de doutorado apresentada à Escola de Enfermagem Anna Nery, na linha de Pesquisa em Educação e Enfermagem, balizado na Teoria de Valor. Devido ao desgaste obtido pela palavra valor ao longo do tempo, passando a ter os mais variados significados, faz-se necessário, a fim de dirimir qualquer dúvida, conceituar este termo. Assim, apropriamo-nos de Werneck, ${ }^{1}$ ao dizermos que: valor é aquilo que vale para o homem, sendo capaz de suprir uma carência e promover o crescimento e desenvolvimento enquanto pessoa.

Desta maneira, o objeto de estudo versa sobre a valoração dada pelo enfermeiro-docente no ato de educar e que ele transmite ao educando de enfermagem. Enquanto ser valorativo, é por meio do discurso que o enfermeiro apresenta ao educando o campo axiológico que funda a profissão, reconhecendo-o em estado de carência para os valores da Enfermagem e encaminhando-o para o crescimento e desenvolvimento enquanto Ser-enfermeiro.

A Enfermagem Moderna possui um conjunto de valores do qual se nutre para elaborar uma escala hierarquizada, dando ao agir profissional sentido e significado. Estes valores foram identificados por Florence Nightingale como instituintes da Enfermagem, formando uma amálgama, a saber: o valor social, o valor ético, o valor útil e o valor verdade. Logo, torna-se impossivel dissociá-los da Enfermagem sem que se destituam do que são.

0 presente estudo tem por objetivo compreender o valor ético, no discurso do enfermeiro-docente, diante do ato de educar e que ele transmite ao educando e, discuti-lo à luz dos pressupostos de Max Scheler. Parte-se do princípio que é por meio do discurso emitido na prática pedagógico-assistencial que o docente apresenta ao educando o valor.

A justificativa está centrada na premissa de que, ao contemplarmos o cenário e o contexto em que vive a sociedade brasileira, esta está marcada pela dicotomia entre o discurso e a prática, pelo descrédito aos valores do justo, da verdade, da ética, do respeito à dignidade da pessoa humana; inferimos que esses fatores agravantes poderão assumir um impacto negativo na formação de profissionais de enfermagem.

\section{REFERENCIAL TEÓRICO}

A fenomenologia de Max Scheler, tendo sua inspiração em Husserl é, antes de tudo, uma filosofia dos valores. Sua pretensão é construir uma ética em base de dados objetivos e rigorosos de onde surja uma axiologia de fundamentos absolutos, opondo-se, de forma radical, ao racionalismo axiológico.

Neste sentido, Costa ${ }^{2}$ afirma que a filosofia desenvolvida por Scheler traz uma nova perspectiva para o campo do conhecimento filosófico, ao afirmar que a racionalidade não é capaz de abarcar em si toda a amplitude da realidade, pois, além do ser-objeto, existe o ser-ato. 0 primeiro é objetivável, o outro não.
Assim, a verdadeira filosofia deve admitir uma forma complementar de participação na essência das coisas, a partir da via emocional. Esta passa a constituir-se em um elemento capaz de produzir o conhecimento do ser.

Ao proceder à reflexão sobre o agir humano, buscando estabelecer uma nova base para a sua compreensão, Scheler ${ }^{3}$ percebeu que havia um tipo de conhecimento cujos objetos eram inteiramente inacessíveis à razão: o conhecimento dos valores.

Para Scheler ${ }^{3}$ os valores são revelados através da intuição emocional. Agindo assim, está rejeitando a distinção entre o conhecimento sensitivo e o racional, elevando o emocional ao nível do racional, admitindo um mundo de experiências cujos objetos são inacessíveis ao entendimento, e que só o emocional coloca o homem autenticamente diante desse mundo.

Ao estabelecer a base de fundamentação de sua filosofia a partir da intuição emocional, Scheler ${ }^{3}$ está realizando uma crítica à concepção ética advinda do formalismo kantiano e propõe uma nova fundamentação.

\section{Oformalismo kantiano}

Analisando os princípios da consciência moral, Kant concluiu que a vontade humana é verdadeiramente moral quando regida pelos imperativos categóricos. 0 imperativo categórico é assim chamado por ser incondicionado, absoluto, voltado para a realização da ação, tendo em vista o dever.

Aranha ${ }^{4}$ afirma que Kant rejeita as concepções morais que predominam até então, quer seja da filosofia grega, quer seja da cristã, e que norteiam a ação moral. 0 agir moralmente se funda exclusivamente na razão. Alei moral que a razão descobre é universal, pois não se trata de descoberta subjetiva, e é necessária, pois é ela que preserva a dignidade humana.

Desta maneira, a autonomia da razão para legislar supõe a liberdade e o dever. Todo imperativo se impõe como dever, mas essa exigência não é heterônoma - exterior e cega -e, sim, livremente assumida pelo sujeito que se autodetermina.

\section{A critica Scheleriana}

Para Scheler, ${ }^{3}$ sua ética material dos valores distingue-se da ética formal kantiana, bem como não se coaduna com a ética defendida pelos filósofos antigos ou com pensamento moderno, residindo nesta nova compreensão sobre o conhecimento do valor - afirmando que somente a intuição emocional permite ao homem ter acesso ao mundo dos valores - a originalidade de seu pensamento.

Scheler ${ }^{3}$ afirma que o conhecimento do valor se dá de maneira a priori, fundando-se em sua objetividade, característica que sustenta a axiologia Scheleriana.

Desta maneira, o mundo dos valores passa a gozar de validade independente do sujeito, constituindo um mundo em si, cujos valores se escondem por trás do sentimento de valor, como dado objetivo e material.

\section{$O$ valor ético e 0 ato de educar do Enfermeiro- docente}

Para Werneck', o valor ético é o bem que se apresenta exigindo uma intenção de amor. Realiza-se, na prática social, 
através das boas obras. Enquanto valor, projeta-se no mundo, elaborando a moral.

O valor moral é sempre um dever-ser, exprimindo-se sob a forma de um imperativo categórico. Impõe-se ao que com ele se depara trazer para o campo de ação sua respectiva influência e, com isso, retificar o seu agir. Logo, torna-se possível transformar a realidade, a partir do crescimento espiritual resultante da presença do bem no interior de cada um. Prosseguindo em sua reflexão, afirma que o ser humano sente a necessidade do bem e, naturalmente, tende para ele, enquanto valor. Sob esse aspecto, o bem se apresenta como fim. A razão, a partir da reflexão, vai estabelecendo uma consciência moral que se expressa pelos juízos de valor que se apresentam à vontade, levando a buscar o bem como seu objetivo.

Para a Enfermagem, este valor coopera para a construção do Ser-enfermeiro, dando-lhe a possibilidade de conferir à sua atitude uma significação centrada na prática do bem. Logo, o assistir à vida ganha uma dimensão que transcende ao biológico, pois o respeito, a dignidade, a honestidade, a integridade moral passam a ter uma exigência na atitude do Ser-enfermeiro. 0 profissional de enfermagem está comprometido com o atendimento ao homem em sua dimensão espiritual. Cabe ao enfermeiro-docente apresentar o valor ético a seu educando.

Freire ${ }^{5}$ afirma que a ética é inseparável da prática educativa, não importa se trabalhamos com crianças, jovens ou com adultos, que devemos lutar. A melhor maneira de por ela lutar é vivê-la em nossa prática, é testemunhá-la, vivaz, ao educando em nossas relações com eles. O educando é encaminhado a incorporar em seu agir uma atitude que expressa o valor ético e, consequentemente, passa a reconhecer o outro enquanto pessoa ao mesmo tempo em que forja o seu caráter, fazendo-o crescer em sua sensibilidade diante da vida.

Este processo é fundamental para que as experiências subjetivas da vida - como, por exemplo, a dor, o sofrimento, a alegria, o amor - passem a adquirir sentido para o educando diante da assistência por ele prestada ao cliente. Desta maneira, ele constrói e apreende o significado de Ser-enfermeiro. A ação assistencial do educando ao cliente passa a ser objeto de avaliação, com o intuito de observar sua adequabilidade à premissa de que a compreensão do outro se dê, não enquanto objeto, mas na perspectiva de pessoa.

Se apreendido o valor ético, este é instaurado na prática assistencial, possibilitando que o educando cresça e desenvolvase na profissão. Igualmente, torna-se necessário que, no exercício de seu ato de educar, o enfermeiro-docente tenha o desejo de apresentar de forma atrativa o valor ético a seu educando.

Elucida a compreensão desta asser tiva a consideração de Freire ${ }^{5}$ ao dizer que a necessária promoção da ingenuidade à criticidade não pode ou não deve ser feita à distância de uma rigorosa formação ética ao lado sempre da estética. Logo, cabe ao enfermeiro-docente valer-se dos mais variados recursos instrucionais para realçar a beleza do valor ético, intentando encaminhar o seu educando ao campo de sua vivência.

0 ensino a respeito da Ética não deve centrar-se exclusivamente na Disciplina de Ética Profissional. 0 aprendizado ético não é restrito a uma disciplina. Faz parte do conteúdo de todas as disciplinas, sobretudo aquelas especíicas da formação profissional de enfermagem. É o refletir da imagem do Ser-enfermeiro que existe em cada docente. Outro aspecto importante no ato de educar, no que pese a apresentação do valor ético, é que este necessita ser desenvolvido na prática pedagógica de modo a favorecer o surgimento de uma formação profissional em que o educando desenvolva a consciência crítica sobre vida, possibilitando-lhe refletir sobre os diversos apelos com os quais se confronta ao longo de sua trajetória profissional, o que lhe permite tomar a decisão certa em todo o ciclo que compõe a vida humana quer seja na fecundação ou na assistência à morte, zelando pela promoção, preservação, manutenção, tratamento e restauração do bem-saúde, enquanto expressão da vida.

Diante do desafio imposto pela formação do educando de enfermagem, faz-se necessário que o enfermeiro-docente direcione o seu ato de educar para que este rompa os lindes do instrucionismo. Há uma crise no processo educativo da enfermagem quando a educação se restringe à instrução, realidade que ele não pode ignorar.

É salutar a consideração de Rodriguez ${ }^{6}$ ao estabelecer a distinção entre instrução e educação, dizendo que instruímos alguém quando the ensinamos técnicas e teorias. 0 ato de educar pressupõe, da parte de quem educa, a vivência de determinados valores. Da parte de quem é educado, a assimilação dos mesmos.

É fácil visualizarmos o descaminho do instrucionismo no cenário nacional, a partir do momento em que se constata, na prática assistencial, a insensibilidade do profissional diante da preservação, promoção, prevenção, restauração da vida humana, cedendo aos apelos do valor econômico. Desta maneira, não se forja o profissional de enfermagem se não houver o seu devido encaminhamento ao campo axiológico que cerca a profissão.

\section{METODOLOGIA}

A pesquisa é de natureza qualitativa com enfoque fenomenológico. Os cenários da pesquisa foram três instituições de ensino superior de Enfermagem, localizadas na cidade do Rio de Janeiro. 0 estudo foi realizado no período de agosto de 2007 a junho de 2008. A seleção dos sujeitos obedeceu ao critério de que os enfermeiros deveriam estar atuando em alguma disciplina na graduação. Participaram do estudo sete docentes que foram identificados como E1 a E7.

As técnicas empregadas para a realização foram: a entrevista semiestruturada e a observação sistematizada. 0 estudo submeteu-se ao Comitê de Ética e Pesquisa da Escola de Enfermagem Anna Nery/UFRJ, registrado com o número 
O Valor Ético IIO eIISIIIO da Elifermagem

Gimarães GL, Viana LO

026/07, sendo considerado aprovado em reunião ocorrida em 24/04/2007. Os dados foram obtidos e utilizados com o consentimento dos envolvidos, em observância ao disposto na Resolução 196/96 do Conselho Nacional de Saúde (CNS).

Ajustificativa da escollha da técnica de entrevista encontrouse apoiada na consideração de Minayo ${ }^{7}$ ao afirmar que a pesquisa qualitativa permite ao pesquisador adentrar no mundo vivido dos sujeitos, buscando compreender, a partir de seus discursos, os sentimentos, valores, ideologias que o permeariam.

A entrevista fenomenológica possui peculiaridades que precisam ser consideradas, a fim de que se tenha o rigor necessário para a sua utilização ${ }^{8}$. Assim, exigiu-se dos pesquisadores a necessidade de percepção no sentido de: 1 ver e observar, desprovidos dos pré-conceitos, mantendo-se em uma relação empática, caracterizada por um estado de aproximação, valorizando e respeitando cada um; 2-interpretar, compreensivamente, a linguagem do entrevistado e sua significação, apoiando-se em uma escuta ativa, mantendo-se receptivo; 3- evitar julgamentos que pudessem interferir na narrativa dos entrevistados.

As entrevistas foram gravadas em fitas magnéticas com a finalidade de garantir a fidedignidade das falas dos sujeitos, cooperando para a sua posterior transcrição. Os dados foram analisados a partir da técnica de análise de discurso proposta por Orlandi?.

A discussão seguiu-se pelos pressupostos da Teoria de Valor segundo Max Scheler, a fim de obter a análise compreensiva, permitindo desvelar o fenômeno presente no discurso do enfermeiro-docente.

\section{ANALISE E DISCUSSÃO}

Para Alves ${ }^{10}$, há uma força motriz capaz de transformar as pessoas, levando-as a assumir uma atitude pró-ativa diante do processo pedagógico e da vida. Esta força é o amor. Sua aparição dá-se na vida social, a partir da relação estabelecida entre as pessoas, instaurando o valor ético.

Ratifica esta afirmativa a consideração de Scheler ${ }^{11}$ ao dizer que o amor aparece aqui apenas como um ' $X$ ' na vida do sentimento, como aquilo que conduz os homens às ações úteis para a comunidade ou, por exemplo, como disposição para tal. Neste sentido, o fundamento para a instauração do valor ético, na Enfermagem, radica-se na perspectiva do desenvolvimento deste sentimento, por parte do docente e do educando, diante da vida, e junto ao cliente. 0 passo inicial assumido pelo enfermeiro-docente deverá ser o de proceder ao movimento reflexivo sobre a prática pedagógico-assistencial, intentando compreender e ajuizar a adequabilidade ética nas ações desenvolvidas por ele e pelo educando na enfermagem.

É ali, no cotidiano, na relação com o cliente, que o docente extrai a esperança de ver o discente crescer e desenvolver-se no valorético que funda a profissão, rompendo com a indiferença, a insensibilidade e a insatisfação no desempenho da prática assistencial da enfermagem. llustra esta assertiva a consideração de E1 ao dizer que:

Hoje você tem alunos que vão embora quando chega o horário e deixam de prestar o cuidado [...] alunos que não conseguem envolver-se com o cliente [...] aí eles acabam se formando [...] você as vê na prática distanciadas dos clientes [...].(E1)

Para o depoente, o educando necessita refletir sobre a sua atitude para com o cliente, buscando construir uma alternativa ao agir com indiferença na prática assistencial. Por meio do discurso, o docente apresenta sua insatisfação ao paradigma visualizado. Sua contrariedade vincula-se diretamente ao significado que o educando atribui à vida humana. Assim, o docente, após confrontar-se com a escala valorativa do educando, vai produzindo o juízo de valor sobre a sua adequabilidade ou não, diante do campo axiológico que funda a profissão, no que pese o valor ético.

Agindo assim, o enfermeiro ratifica a proposição Scheleriana de que é por meio da reflexão sobre a escala de valor que se constrói a possibilidade da pessoa, em retificar o agir, se assim o desejar, pois, para Scheler ${ }^{11}$ a eticidade se baseia na eterna hierarquia dos valores, e nas valorações preferenciais que evidentemente correspondem a ela, sendo que estas são tão objetivas e rigidamente inteligíveis quanto às verdades matemáticas. Logo, a re-hierarquização do valor é situação ímpar para a transformação da atitude expressada pelo docente e o educando em relação à enfermagem.

Prosseguindo na análise do discurso, a partir do não dito, é possível traçar o perfil que o docente aspira ver surgir no educando. Ele deseja que o educando seja: comprometido com o cliente; que reconheça a dignidade da pessoa humana; que estabeleça uma atitude de respeito. Agindo assim, o enfermeirodocente reafirma que o modelo aceito para a formação do acadêmico está centrado no valor ético que funda o campo axiológico da profissão.

Desta maneira, urge para o enfermeiro-docente fazer com que o educando proceda ao movimento de reflexão e retifique o seu agir, se assim o desejar, a partir da incorporação do valor ético.

Assim, pode-se constatar, na palavra em movimento de E5, o quanto é imprescindível para ele desenvolver, no ato de educar em enfermagem, o ensino sobre o valor ético, assumindo um sentido de dever-ser, a fim de que seja proporcionado o pleno crescimento e desenvolvimento do educando na profissão.

Esclarece a esta afirmação o recorte do discurso de E5 ao dizer que

[...] dentro da formação, acima de tudo eles têm que respeitar; ter uma atitude que demonstre 0 que é a enfermagem [...] fazendo do cuidado uma oportunidade de dar carinho [...].(E2)

Para o depoente, a competência técnica, advinda da 'formação', vincula-se de maneira direta à competência ética. 
Não basta saber fazer, é necessário saber relacionar-se com o cliente, reconhecendo neste o valor de pessoa.

Coopera, para a elucidação do discurso, o pensamento de Werneck ${ }^{1}$ ao afirmar que o valor ético emerge na prática a partir do desenvolvimento e crescimento da pessoa no amor.

Desta maneira, o enfermeiro-docente, ao identificar o cuidado sob o prisma de "dar carinho", enquanto expressão do sentimento - amor, faz emergir na prática assistencial, o valor ético, manifestando-o no agir em relação ao cliente. $O$ valor ético é visualizado nas relações sociais entre as pessoas, assumindo um sentido de obrigatoriedade para o homem para que possa crescer e desenvolver-se enquanto pessoa, ao mesmo tempo em que se constitui no elemento primordial para que se processe a transformação da realidade ${ }^{11}$. Logo, o valor ético constrói a base sobre a qual se estabelecem as diversas atitudes que permitem o aprimoramento do Ser-enfermeiro em sua relação com o cliente, construindo a lei moral que passa a orientar as ações do enfermeiro.

0 enfermeiro está convicto de que o cliente não pode ser percebido pelo educando, em sua prática assistencial, exclusivamente sobre o prisma do atendimento de suas necessidades biológicas, mas avança para a sua compreensão enquanto ser biopsicossocial; ser que aspira ao reconhecimento enquanto pessoa.

Cabe ao docente, no ato de educar, reconhecer o educando como ser dotado de carência axiológica para os valores da enfermagem, empenhando-se em apresentar o valor éticoao educando, para que possa crescer e desenvolver-se enquanto Ser-enfermeiro, possibilitando-lhe a complementaridade, a partir da instauração deste valor em suas ações.

É salutar a consideração de Teles ${ }^{12}$ ao afirmar que só se pode dar o que se tem. Quem não é livre, jamais poderá propiciar liberdade. Quem não ama, não pode dar respeito, sinceridade. É pelo exemplo que o enfermeiro-docente dá a visibilidade do valor ético ao educando, ao mesmo tempo em que só poderá fazê-lo se estiver em estado de reflexão permanente.

0 docente promove o enlace entre o discurso e o agir certo, apresentando o valor ético como instituinte para a assistência, permitindo que o cuidado de enfermagem se revista de uma dimensão empática. Não se trata de uma apresentação calcada nas normas escritas no Código de Deontologia. Mas avança para a demonstração no campo da prática assistencial. 0 discente necessita visualizar o enlace entre o discurso e 0 fazer. Freire ${ }^{5}$ corrobora esta assertiva ao dizer que a melhor maneira de apresentar o significado do ético é vivê-la na prática, é testemunhá-la aos educandos. Desta maneira, o docente constrói, a partir do ato de educar, a oportunidade de um encontro dialógico com o educando, e o encaminha para a reflexão sobre o agir profissional em relação ao cliente.

Prosseguindo na análise do discurso do enfermeiro-docente, a partir dos discursos emitidos por E1, E2, E3, E4, E6 e E7, pode-se compreender o quanto é valioso prover ao educando a possibilidade de transformação de paradigma, a partir de seu crescimento e desenvolvimento, no valor ético.
Trago os recortes dos discursos para exemplificar a afirmativa:

[...] ainda hoje, é valorizado muito o procedimento! A sensibilidade ao outro é apenas mais um ponto no critério de avaliação [...] você as vê na prática distanciadas dos clientes [...] (E1).

\section{[...] vejo que o desenvolvimento docente dentro de nossa profissão é de fundamental importância para que possamos construir uma Enfermagem [...] competente tecnicamente, mas também eticamente competente (E2).}

\section{[...]. não dá para pensar em formar profissionais da área da saúde sem pensarno compromisso [...] tendo um agir pautado pela ética, no respeito ao outro! [...] (E3.)}

Eu procuro transmitir a eles esta ideia da solidariedade e da preparação que a gente necessita ter para desenvolver, indo além deste sentimento da solidariedade com caráter; com respeito ao outro; com dignidade [...](E4).

\section{[...] Eles não veem como importante a mudança de atitude. Eles não se preocupam em mudar (E6).}

\section{[...] O que eu mais cobro deles é que eles tenham postura; que eles tenham ética [...] mais do que realizar o procedimento, eu falo com eles que a habilidade virá com o tempo - eles precisam ter postura (E7).}

Constata-se a crítica do enfermeiro-docente ao modelo de formação centrado exclusivamente no modelo biologicista, manifestado na assistência a partir do rigor técnico, que compõe a profissão. Para ele, tal ênfase acarreta uma deformação no significado atribuído pelo discente sobre a enfermagem, e, consequentemente, a enfermagem por ele desenvolvida, impedindo-o de aprimorar-se enquanto Ser-enfermeiro.

Os depoentes acreditam que o processo de transformação da prática assistencial está alicerçado sobre o crescimento e desenvolvimento do educando no valor ético. Desta maneira, buscam, através do ato de educar, despertar no discente a capacidade de reconhecer a singularidade que compõe o Serenfermeiro.

Neste sentido, o enfermeiro-docente, ao propor o enlace entre a competência técnica e o valor ético, ratifica a proposição de Scheler de que o valor éticoé o fundamento para a transformação da realidade ${ }^{13}$. 
O Valor Ético IIO eIISIIIO da Elifermagem

Gimarães GL, Viana LO

\section{CONCLUSÃO}

Chegado-se ao término das considerações, pode-se concluir que o enfermeiro-docente, em sua prática pedagógicoassistencial, apresenta, por meio de seu discurso, o Valor Ético ao educando. Para o docente, a aparição na pragmática assistencial deste valor permite desenvolver no educando a sensibilidade sobre as questões da vida em suas diversas etapas,

\section{REFERÊNCIAS}

1-Werneck VR. Educação e sensibilidade. Rio de Janeiro (RJ): Forense Universitária; 1996.

2-Costa IS. Max Scheler: o personalismo ético. São Paulo (SP): Moderna; 1996.

3- Scheler M. Le formalisme en éthique et l'ethique matériale des valeurs. Paris (FR): Gallimard; 1955.

4- Aranha MLDA. Filosofando: introdução à filosofia. $3^{a}$ ed.São Paulo (SP): Moderna; 2003.

5-Freire P. Pedagogia da autonomia. $33^{\mathrm{a}}$ ed. São Paulo (SP): Paz e Terra; 2006

6- Rodriguez RV. Educação e sensibilidade.[prefácio] Rio de Janeiro (RJ): Forense; 1996.

7-Minayo MC. Pesquisa social: teoria, método e criatividade. $23^{\mathrm{a}} \mathrm{ed}$. Petrópolis (RJ): Vozes; 2004. indo da concepção até a morte, permitindo-lhe compreender o cliente, não enquanto objeto, mas como pessoa. Assim, o educando tem a oportunidade de refletir sobre a prática assistencial, buscando comprometer-se eticamente com aquele a quem dirige o cuidado, participando ativamente na construção de um novo paradigma assistencial para a Enfermagem.

8-Carvalho ADS. Metodologia da entrevista: uma abordagem fenomenológica. Rio de Janeiro (RJ): Agir; 1991.

9-Orlandi EP. Introdução a análise do discurso. São Paulo (SP): Unicamp; 2003.

10- Alves R. Conversas com quem gosta de ensinar. Campinas (SP): Papirus; 2006.

11-Scheler M. Da reviravolta dos valores. Tradução de Marco Antonio dos Santos Casa Nova. Petrópolis (RJ): Vozes; 1994.

12-Teles MLS. Educação: a revolução necessária. $5^{a}$ ed. Petrópolis (RJ): Vozes; 2001.

13-Guimarães GL. 0 perfil do enfermeiro-educador para o ensino de graduação. Esc Anna Nery Rev Enferm 2005 ago; 9(2): 255-60. 